\title{
Reducing Discretion in the Administration of Prison Leave: In Search of Legitimacy
}

\author{
Elena Larrauri ${ }^{1}$ \\ Published online: 22 August 2019 \\ (C) The Author(s) 2019, corrected publication 2019
}

\begin{abstract}
This paper explains the institution of prison leave in Spain. Firstly, I will briefly describe the regulations governing prison leave and provide data on its use in Spain. I will point out that although half the prison population benefits from a prison leave, a main problem is that it is granted at a very late stage of the sentence, and that immigrants have a very low probability of obtaing it. Secondly, I will explain the criteria used in order to determine if a leave is granted, the wide discretion that psychologists in particular enjoy, and why this procedure might be experienced by the prisoner as unfair. Thirdly, I will describe the mixed system that allows both Prison Boards and Judges to make decisions about leave and how this often produces confusing results for prisoners. For instance, a positive prison report being followed by a negative judicial response due to the wide discretion that judicial authorities also enjoy. Finally, I draw some tentative conclusions about how a lack of clear criteria and procedure in relation to prison leave might also affect legitimacy in prison.
\end{abstract}

Keywords Prison leave $\cdot$ Rights $\cdot$ Privileges $\cdot$ Discretion $\cdot$ Legitimacy

\section{Introduction}

'They invent their laws... this is not a fair prison' [Prisoner interview]Prison leave in Spain, is a temporary release permit for inmates serving a sentence in closed prisons for the purpose of

This paper is part of the project Ejecución y supervisión de la pena: Calidad de la intervención, legitimidad y reincidencia supported by the Spanish Ministry of Economy and Competitiveness, Grant DER2015-64403-P and FEDER, UE; also supported by Ayudas a las acciones de dinamización "Redes de Excelencia": Desarrollo de un modelo criminológico y empírico de la política criminal - Acrónimo EmpiriC - . Financiado por MCIU-AEI (Ref. DER2017-90552-REDT). It was presented at the Criminal Law Faculty Seminar in NYU in 2017, and The Howard League Seminar (Oxford, 2018). I thank both institutions, and specially James Jacobs and Ian Loader, for the opportunity they gave me. Martí Rovira is the author of the Figures and Andrew Henley is my best editor.

Elena Larrauri

elena.larrauri@upf.edu

1 University Pompeu Fabra, Barcelona, Spain 
allowing inmates to keep ties with their family and to provide a brief contact with the community. The object of my research is not a prison leave granted for extraordinary humanitarian reasons (i.e., attending a funeral), but 'ordinary' prison leave.

In some countries prison leave is linked to attending certain programs (educational, occupational, or attendance at a specific detox program). However, in Spain the Penitentiary Law states that the main justification for prison leave is for the prisoner to keep links with their family and the outside world in order to prepare for release. In Spain, the duration of prison leave for an inmate in a closed prison ${ }^{1}$ is up to 36 days a year, and these are usually granted on weekends.

The introduction of this institution in Spain is linked to the humanization of the penitentiary system undertaken by Victoria Kent and the introduction of the 'progressive system'. In the Prison Regulations of 1956, extraordinary prison leave was recognized for humanitarian reasons (for example, attending a funeral). Ordinary prison leave was introduced in further regulations in 1977 for the first time, 'to carry out family visits'. However, there is an additional historical reason which possibly explains why ordinary prison leave was introduced at that time. In 1977, political prisoners were granted amnesty after Franco's death and the introduction of prison leave may in part have been to 'compensate' common prisoners, who at that time were excluded from the political amnesty (Civil servant, personal communication 9/12/2016).

Since its introduction, prison leave has been widely used, as we will see in the next section. In addition, some research tends to show a positive link between prison leave and recidivism rates. For example we know that in Catalonia (CEJFE, 2015) prisoners that have enjoyed a prison leave have a recidivism rate of $20.5 \%$, whereas those who have not have a $38.6 \%$ rate. ${ }^{2}$

A prison leave is vital because in Spain, as in other European countries (Mine and Robert 2015), it might imply the first step of 'progression' of the sentence. That is, before being sent to an 'open prison', or granted 'conditional release', the prison administration tends to require that prison leave has been previously granted and carried out with no incidents. Recent research showed that for those granted a leave, 56.5\% were released early (to an open regime or on conditional release), compared to only $10 \%$ of those who had not been granted leave. From this data it can be confirmed that the key element of the Spanish system of early release begins with a prison leave (Cid and Ibàñez 2019).

Prison leave is also justified for the positive effects it might have for prison life. It is defended because it brings hope inside the prison wings ${ }^{3}$ and a more positive attitude to prison. ${ }^{4}$ According to ground-breaking research done by Downes (1988:183) comparing English prisons with the Dutch prison system, the author identifies home leave "as the cardinal

\footnotetext{
${ }^{1}$ In $2017,81.5 \%$ of prisoners are in ordinary regime (closed/medium security), whereas $16.2 \%$ are in open prison (spending all day out, returning to prison to sleep) and $2.2 \%$ are in maximum security. This last group are the only ones legally excluded from prison leave. Prisoners in open prison may enjoy 48 days a year prison leave, in addition to weekend leave.

${ }^{2}$ However, maybe this research needs to be refined since we do not know what other characteristics these two groups have and the danger of (self) selection is obvious. It is necessary to study precisely the positive effect of prison leave because there are few studies on this topic and some of them lump together every kind of outside contact or expand conclusions drawn from parole to prison leave. See Cheliotis (2005, 2009); Baumer et al. (2009); Moran and Keinänen (2012); Helmus and Ternes (2017).

${ }^{3}$ However, prison leave also brings problems because the prisoners that go out on leave might be pressured by other inmates to smuggle things in. Therefore, sometimes prison managers might put them together on a wing, sometimes called by other inmates, 'chicken wing'.

${ }^{4}$ It is also useful for administrators, as an indicator of 'performance' of the different treatment personnel (personal communication). This is because prison leave is directly linked to participating in a cognitive behavioral programs.
} 
feature of the greater commitment of the Dutch system to prisoners welfare" (emphasis in the original). Several reports in Europe highlight the contribution of prison leave to good order and less violence in prisons (Dünkel and Van Zyl 2001).

Prison leave also has its critics. The assumption is that they are sometimes used as a tool to keep order and as a 'reward' for 'docility' inside prison (Moran and Keinänen 2012). This is not far-fetched because in Spain and other countries prison leave in prison law has often been regulated under the heading of 'rewards'. The fear probably is not so much that prison leave should be earned, or should be used as a tool to motivate change, but that it could be used to reward behavior that might be useful to keep order inside prison with little relation to rehabilitation efforts.

In sum, prison leave is a defended institution by academics, the Courts and the prison Administration in Spain, because it is assumed it favors reintegration and reinforces the offenders' decision to change; because it is the first step for progression of the sentence; and because it brings hope inside the prison. In addition, total isolation of inmates from the outside world is not supported by our core humanitarian values. In a penal system that, in 2016, has $27 \%$ of prisoners serving long-term sentences (from five to ten years) compared to $6.9 \%$ in Germany, and an average of time spent in prison of 17.5 months (compared to 8.1 months in Germany), the institution of prison leave is also particularly relevant for reasons of humanity and to mitigate some of the negative psychological effects of long term imprisonment. In Spain, the final assumption is that a prison system with prison leave will be both more humane and more successful in the reintegration of offenders.

\section{Regulation and Application of Prison Leave in Spain}

In Spain, the penitentiary law requires three 'objective' elements to be satisfied prior to an application for a prison leave: $1 / 4$ time of the sentence served, medium security classification and good conduct. ${ }^{5}$

In our research (Rovira et al. 2018), based on 152 interviews with prisoners, we discovered that only $25.3 \%$ of the inmates in the ordinary regime enjoyed a leave after $1 / 4$ of the sentence was served, rising to $34.1 \%$ at the middle of the sentence, and only after the $3 / 4$ stage had been reached did the proportion rise to $51.5 \%$ of inmates (see Fig. 1). These data lead us to be critical of the way in which this institution is being used, since only $25.3 \%$ benefit from the progressive system, as this was theoretically conceived. In its origins the progressive system envisaged the granting of prison leave at the $1 / 4$ stage of the sentence, a move to an open prison by the halfway stage, and to be conditionally released at the $3 / 4$ stage. This led us to conclude that in practice, by operating in the last part of the sentence, prison leave in Spain tends to replace the open regime and conditional release, rather than allowing for an adequate use of the progressive system. ${ }^{6}$

The legal discussion has tended to focus on the condition of $1 / 4$ of the sentence having been served for a leave to be granted. Indeed, the Constitutional Court has reinterpreted that it is constitutional to deny a prison leave if the prisoner is not 'close to release date'. The judgment of January 13th, 1997, understood that the criterion of 'long distance to the final date of the

\footnotetext{
${ }^{5}$ Some of these criteria might be more objective than others, although the requirement of good conduct has been 'objectivised' by requiring the prisoner not to have a recent disciplinary offence.

${ }^{6}$ The same conclusion can be seen in other countries. See Mine and Robert (2015).
} 


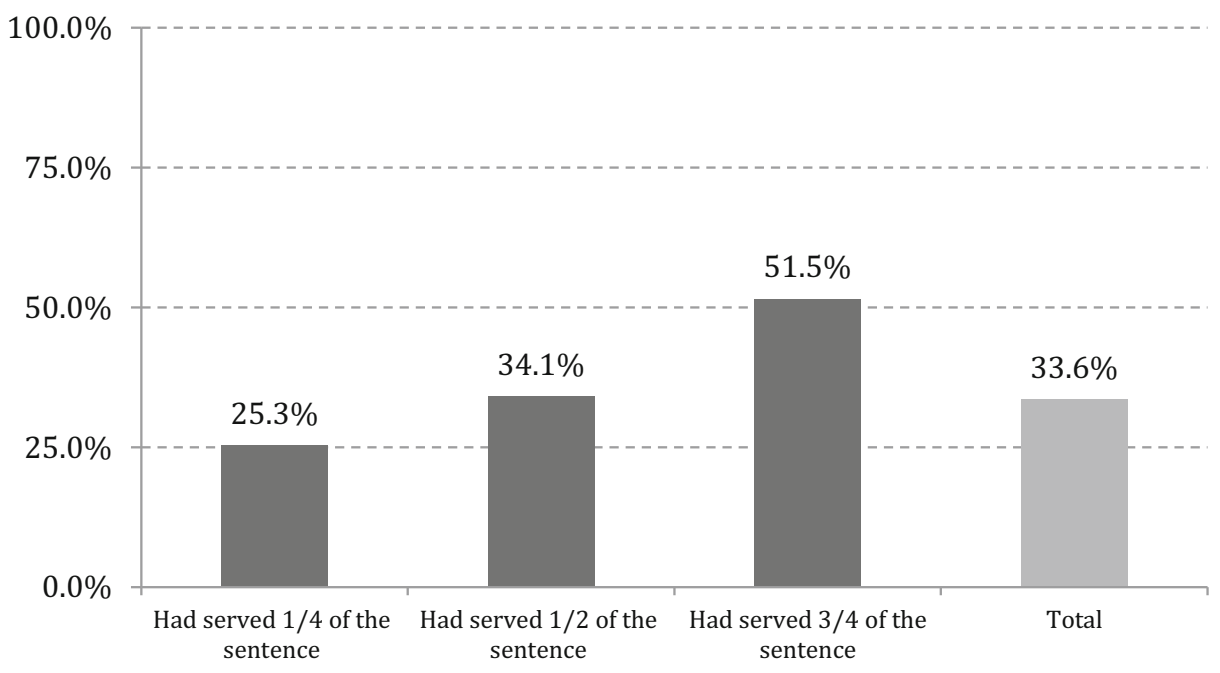

Fig. 1 Proportion of inmates who have enjoyed a leave by stage of the sentence

sentence' is not manifestly arbitrary since it is related to the purpose of the institution, which is to prepare for release. This is now common practice, and according to my research, a common reason to deny prison leave is if the inmate has more than 5 years left (Larrauri 2019).

The arguments against granting it at the beginning of the sentence rest in a retributive notion, that requires a mandatory minimum that a person has to serve before being granted a leave. This probably helps to explain why prison leave is usually granted near the end of the sentence.

There is an additional argument often repeated, such as 'that a remaining long sentence might increase the risk of evasion'. ${ }^{7}$ However, this is denied by the low levels of abscondment by prisoners on prison leave in Spain over the years. For instance, in 2016 inmates did not return in $0.2 \%$ cases of prison leave in Catalonia and in $0.4 \%$ of cases in the rest of Spain (see Fig. 2).

The 'minimum time requirement' does not seem to be supported either by any reintegrative need. The reintegration plan should be from the beginning of the sentence, and the idea that long sentences need not include preparation for release until the end is wrong because it deprives this group of inmates of opportunities to have access to early release mechanisms. So according to my judgement, if we accept the requirement of a minimum time to be served before applying for a prison leave, a good starting point could be Germany that requires 6 months to have been served (van Zyl Smit 1988:6).

Regarding who will receive prison leave we have no data, and can only speculate. However, we know who will almost certainly not get prison leave. If we take a closer look and we disaggregate the data by nationality, we find that for those inmates at the

\footnotetext{
${ }_{7}^{7}$ Paradoxically however, in Spain we accept an initial Security Level Assignation to an open prison while denying a prison leave at the beginning of the sentence.
} 


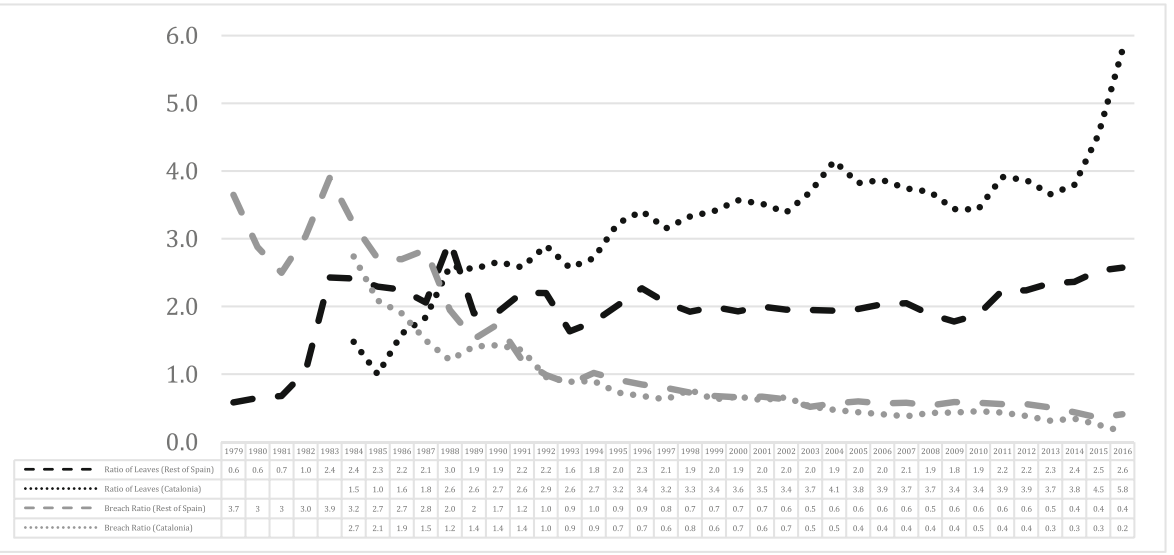

Fig. 2 Leave rate ${ }^{1} \&$ breach ratio $^{2}$ Catalonia \& rest of Spain 1979-2016

end of their sentence, over $74.7 \%$ had been granted leave in the case of EU nationals, while only $21 \%$ of non-EU nationals had enjoyed leave (Rovira et al. 2018) ${ }^{8}$ (see Fig. 3).

Regarding offence-based exclusions from prison leave, in Spain no offence is excluded in principle. ${ }^{9}$ However, the seriousness of the offence will most certainly have an impact when calculating the $1 / 4$ stage of the sentence. In addition, if cognitive behavioral programs are not offered until an advanced stage in the case of long-term sentences, the prisoner will not be granted a prison leave until he completes the treatment program (see next section) and will find himself in a closed circle. Furthermore, as we have seen the Constitutional Court accepts that if the prisoner is not 'close to release', this provides legitimate grounds for denying prison leave. Finally, since 2012, gender violence has been introduced as a specific offence that makes it more difficult to be able to enjoy prison leave.

In summary, in Spain the penitentiary law foresees that prisoners may enjoy prison leave in medium security prison at $1 / 4$ of the sentence. However, according to our research at this stage only $25.3 \%$ of prisoners benefit from it, and not until $3 / 4$ of their sentence does this figure rise to $51 \%$ of inmates. Prison leave then tends to be granted at the end of the sentence and in practice substitutes other institutions (open prisons, parole) that should allow early release. This is a problem, because it avoids progression to open prison and to conditional release, so ultimately about $70 \%$ of the prisoners serve all their sentence in a medium security prison (Cid and Ibàñez 2019).

A second clear conclusion of our research is that immigrants tend to be excluded, and approximately only $20 \%$ of immigrants enjoy prison leave. Finally, although no offence is in principle excluded from a prison leave, the seriousness of the offence is considered in multiple ways, in particular through the requirement of a minimum time to be served, through an evaluation of risk or through general anxiety about certain crimes. This raises the question of whether elements that have already been taken into

\footnotetext{
${ }^{8}$ The same has been found in Finland (Moran and Keinänen 2012). In Spain, there have been regulations explicitly aiming to deny leave to immigrants, as a way to 'nudge' their acceptance of returning home.

${ }^{9}$ For example, a life sentence has no prison leave until 8 or 12 years, but they are not excluded from prison leave (art. 36, b of Criminal Code).
} 


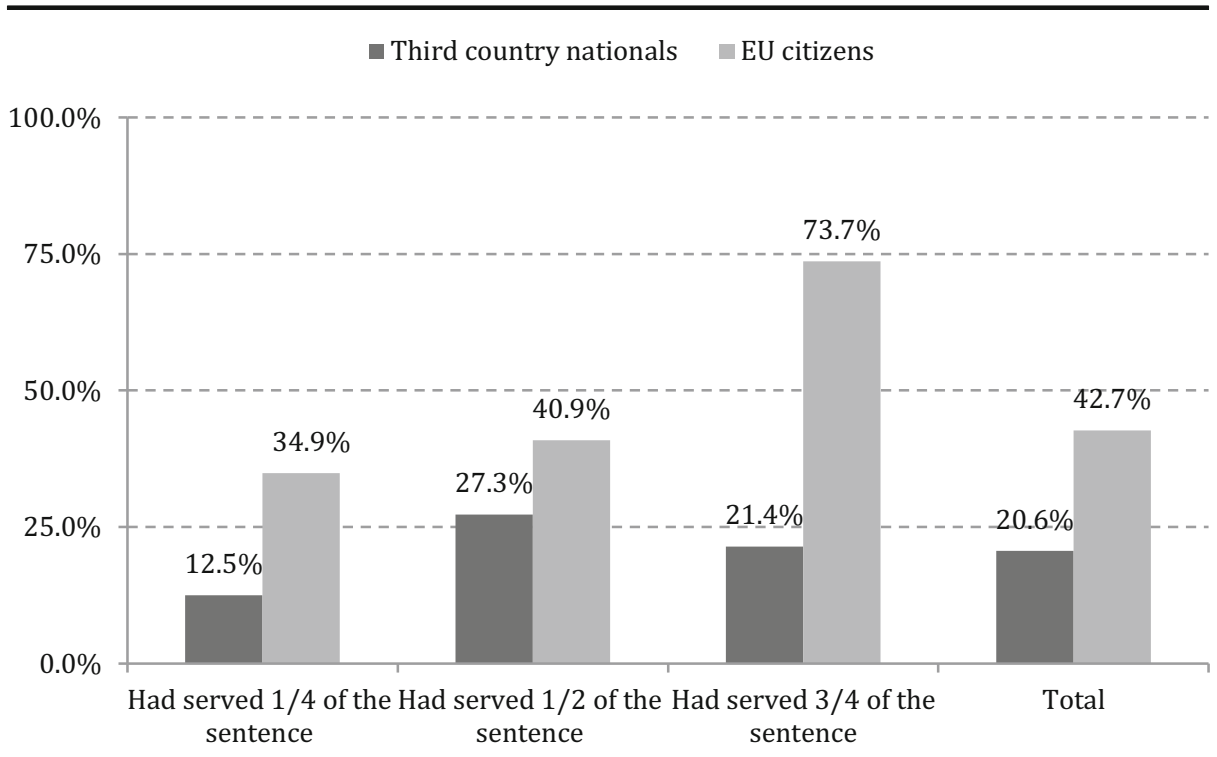

Fig. 3 Proportion of inmates who have enjoyed a leave by stage of the sentence and immigration status

account when sentencing should be considered again at this further stage, when implementing the prison sentence (van Zyl Smit and Snacken 2009).

\section{Eligibility Criteria: 'Chasing Carrots'}

In addition to the three objective criteria already mentioned, to be granted prison leave in Spain requires a number of 'subjective requirements' to also be satisfied. The prison regulations mention the need to evaluate the personality of the prisoner, the nature of the offence and 'other qualitative factors'.

As may be obvious, these criteria create leeway for discretion. This might explain the big differences we find among different parts of Spain. For example, in 2016 we have a total of 156,595 instances of leave granted (to a prison population of 61,000 prisoners), with a ratio of 5.78:1 in Catalonia, and 2.58:1 in the rest of Spain (Rovira et al. 2018; see fig. 2).

The problem of trying to structure discretion or pin down the factors that are used to evaluate the risk of reoffending, evasion or misuse of leave is probably a common challenge faced by all prison administrators. One attempt to resolve these issues in Spain has been through an endless discussion about the 'legal nature' of prison leave. ${ }^{10}$

Many authors have defended its character as a right instead of a privilege. As with many other institutions in prison that allow early release (or an amelioration of the closed regime), to defend that prison leave is a 'right' seems to foster the possibility of granting prison leave 'automatically', for example after a certain period of time. On the contrary, to insist that it is a privilege, seems to open the door for vague criteria, and discretional concessions (based on performance inside prison and/or on an 'individual assessment' based on reintegration efforts).

$\overline{{ }^{10} \text { See a summary of the discussion }}$ in Larrauri (2019). 
However in Boulois v. Luxembourg (2012) the ECtHR discusses whether there is a right to leave (which therefore merits the protection of article 6 of the ECHR), and concludes that the fact that it is discretional does not deny the existence of a right. ${ }^{11}$ Even if the law mentions a 'privilege' this is not the end of the discussion, because a 'privilege' might be something authorities are bound to grant if the requirements are met [par.93-97]. ${ }^{12}$

My opinion is that we should defend prison leave as a right, ${ }^{13}$ because total isolation of inmates is not supported by our core humanitarian values and also because we remain committed to rehabilitation. However, even if we defend it as a right, unless the system is based only on the amount of time served, there will also be the need to balance different factors, such as the reintegration plan, and any measures to minimize the risk of reoffending, abscondment or misuse.

In order to achieve some consistency, risk assessment (RA) tools were introduced in Spain in $1995 .{ }^{14}$ These do not seem to produce an observable impact in the increase or decrease of leave rates (Rovira et al. 2018; see Fig. 2). On the one hand, this is probably due to the fact that inside prison boards there is a persistence of clinical judgement. On the other hand, RA tools do not discriminate enough, because the vast majority of inmates are 'low risk'. ${ }^{15}$

This raises questions of how to structure discretion. In Spain, the Prison Guidelines given to prison boards foresee up to 67 reasons to deny a prison leave. The reasons are so many and so vague, that there is little wonder that prisoners sometimes complain that the procedure is like 'chasing carrots'. Owing to some empirical research in Catalan prisons (Neira 2015) we know that the three most common criteria used to deny prison leave are: a) participation in treatment programs; b) no acknowledgment of the crime; and c) non-payment of the civil liability derived from the offence. A brief critical comment on each follows.

Participation in treatment programs This requirement probably reflects the predominance of the psychological model of rehabilitation inside Spanish Prisons since 1977. ${ }^{16}$ Fox (1999) argues precisely that these cognitive behavioral programs might deliver psychological help but favor a particular psychological explanation that emphasizes human choice and eschews sociological considerations.

Certainly, in Spain the participation in a cognitive behavioral program tends to be a requirement to be granted a prison leave. Although leave may be defined as 'part of the

\footnotetext{
11 The ECtHR ends up in this case denying the existence of a right to prison leave in the jurisdiction of Luxembourg [par.99]. See dissenting votes. See also Decision Jaurrieta Ortigala v. Spain, January 22, 2013, that although there is no right to prison leave, prisoners have a 'legitimate interest'.

12 See also the decision of the Cour de Cassation in Belgium, November 15, 2013, that once all the conditions are met, the permission to leave must be granted (Mine and Robert 2015).

13 Prison leave should also be defended in favor of family life. I thank David Garland for this remark.

${ }^{14}$ For a broad analysis of the introduction of risk assessment tools in European prisons see Snacken et al. (2014:426). For the turn it implied in US for penology see Simon (2000). For criticisms of these tools see, for example, Monahan and Skeem (2016).

${ }^{15}$ However, the use of RA tools has other effects. For example, judges may deny prison leave when they observe a medium or high risk assessment level.

${ }^{16}$ Caballero (1981) describes the entry of the treatment personnel in Spain, paradoxically when the psychological rehabilitation ideology was in decline in the rest of the world. He nicely describes it as a 'clash of elites' between the new treatment personnel and old officers.
} 
treatment', it is not granted unless one has successfully finished the program. ${ }^{17}$ In addition, the person needs to worry about if and when the program is offered, and if he can take part. ${ }^{18}$

According to Crewe (2015:53) "In many jurisdictions, psychological power has superseded coercion as the primary basis for control and compliance". And as the author explains, the way to manage prisons today is based on the manipulation of incentives as a form of 'soft power', more than on physical force (Crewe 2011a).

Of course it is debatable up to which point the coercive regime previous to 1977 in Spain did not also rely on a wide system of rewards (Caballero 1981); however, one further difference might be that the power to give rewards is now located within different occupational groups. The 'power of the pen' (Crewe 2011a) in Spain, if my analysis is correct, does not lie within the uniformed officers but more in the hands of the treatment personnel. ${ }^{19}$

This may help understand why, maybe paradoxically, uniformed officers are better evaluated in Spanish prisons than treatment personnel (similar to other countries, Hacin et al. 2019). Probably because the stakes that depend on these latter personnel are much higher, as is the frustration that concurs when prison leave is denied on grounds of failed participation in cognitive behavioral programs.

Acknowledgment of the offence This is the second most common requirement evaluated in Spain for a prison leave to be granted. I am not sure if the requirement to 'admit/assume your offence' can be traced back to the psychological rehabilitation model inside prison, or if it also has to do with a new general 'moralization' of penal law. ${ }^{20}$

However, it might be worthwhile to note, following Maruna, ${ }^{21}$ that there is a difference between accepting responsibility, providing an account, taking blame, or claiming an excuse. These are all fine distinctions that cannot simply be swept away.

As Maruna and Mann (2006) have argued, there is not enough research into how 'denials' correlate with future offences. Moreover, the fact of using 'excuses' might already be an indicator that the author is 'aligned with the social order'. Therefore we should not discard all the explanations that the offender provides, because there might be a difference between 'good accounts and bad excuses' (Maruna and Mann 2006).

Furthermore, a narrative that makes sense of the past may actually be part of the process of desistance and thus necessary to build on strengths for the future. Therefore, the requirement of these often lumped together and unchallenged assumptions (to accept responsibility, to acknowledge the harm, to accept blame) can have very serious consequences for keeping the 'integrity of the ego', which is crucial for desistance (Maruna and Copes 2004:80).

\footnotetext{
${ }^{17}$ It is difficult to provide accurate numbers of how many prisoners participate in cognitive behavioral programs. According to our previous research (Larrauri et al. 2017) there seem to be important differences between prisons, depending also on what sort of 'programs' are counted. We found that the percentage of inmates declaring participation in a program varied from $30 \%$ to $85 \%$ between four different Catalan prisons, with most inmates referring to cognitive-behavioral and drug addiction programs.

${ }^{18}$ These programs are seen as part of what has been called the 'responsibilization model', more demanding because you have to earn it (Kemshall 2011), signaling that nowadays it is not only necessary not to misbehave but also to engage (Crewe 2015).

${ }^{19}$ This is not to say that officers do not hold any power. Of course they do. For example, they are mainly responsible for disciplinary infractions, and to have a recent disciplinary infraction would undermine any application for prison leave.

${ }^{20}$ By which I mean theories that defend that the goal of punishment is to repent (see Duff 2001, and for a discussion, Schinkel 2014). In terrorism offences there are specific legal provisions that require, in addition, an apology to the victims.

${ }^{21}$ I thank Shadd Maruna for his help.
} 
Non-payment of the civil liability derived from the offence The third most important factor in order to grant prison leave is compensation to the victim. In Spain, since 2003, it is required to pay compensation to the victim, in order to be granted open prison or parole. This was introduced for particularly serious economic crimes, although it has been extended to all offences. Although prison leave was not mentioned when introducing this policy, it is also now a requirement, albeit not a legal one, in order for prison leave to be granted. This is why some prisoners claim: 'I have already paid for my prison leave'. ${ }^{22}$

It is true that it is not required to pay all the compensation owing and sometimes to begin to pay or commit to pay might suffice. However, the amount paid has to show 'evidence' of real remorse. If a payment is judged to be 'manipulative' in order to achieve a prison leave an application may prove unsuccessful. Moreover, since the law is silent on this matter, the fact of not paying the compensation is sometimes reformulated as evidence that the offender is still 'not acknowledging the offence'.

These three are not the only criteria evaluated. Indeed, as we will see in the next section, judges tend to require many other elements before allowing a prison leave. For example, the existence of external social support would be a fourth common element. However, it seems true that the main thrust of the evaluation can be explained by the psychological model of rehabilitation present in Spanish prisons, now compounded with the introduction of the victim into the implementation of the sentence. This model nowadays conceives of prison leave mainly as a 'tool of treatment', which carries within a large degree of indetermination.

Obviously, an 'individual assessment' always contains a certain degree of indeterminacy, but in my view the task of the prison administration is to produce guidelines to define the criteria that guide the policy in the first place (Rodríguez de Santiago 2016) and to supervising the actual practices of different prison boards. Complying with these two duties would give some certainty to the prisoner. ${ }^{23}$ As van Zyl Smit (1988:6), commenting on Germany, states: "Although a prisoner has no right to leave, he has a right to ensure that officials in considering an application for leave exercise their discretion correctly".

Therefore the Administration could produce some guidelines aimed also to achieve some consistency. Following Toch (1967), it would be useful if these criteria would respect some principles such as:

a. Known in advance: by law, soft law, or signed contract. ${ }^{24}$

b. Dynamic: achievable (not based on the offence, time served, or immigration status).

c. Evidence based: the criteria used should reflect a consensus that they serve to measure reintegration efforts (and not only based on the psychological model of rehabilitation).

d. Allowing of intersubjective control: based on facts, stating the relevance attributed to different facts, and disclosure of the sources that have been used (files, risk assessment, and direct interaction).

\footnotetext{
${ }^{22}$ I thank Cristina Güerri for this quote.

${ }^{23}$ It should be stressed that it is not only a matter of allowing judicial review. In my opinion, the prison administration should elaborate and supervise the criteria applied by each single prison board, in order to guide the policy on prison leave.

${ }^{24}$ In Spain prisoners sign a 'contract' where the prison administration states the predictable date on which the prisoner will achieve the prison leave. Although a good idea, the problem is that there is no consequence for the Administration if the contract is not respected.
} 
To sum up, to grant prison leave in Spain requires three elements that are 'objective' $(1 / 4$ sentence served, medium security classification, no disciplinary adjudications), and other 'subjective' elements (the offence, the offender, and 'qualitative variables'). Because of the lack of further precision in prison regulations, this poses a great risk of inconsistency. In order to avoid this, RA tools were introduced in 1995. These have not achieved consistency, and presently there are up to 67 reasons in prison regulations that can be used to deny a prison leave. Many of these requirements are not in the law, and elicit the feeling expressed by some prisoners that 'they invent their laws', as the initial quote of the article states.

I have defended that the multiple criteria used to evaluate a prison leave reflects the prevalence of the psychological model of rehabilitation in Spanish prisons. Insofar, prison leave can be seen as an example of what Crewe (2011a) called 'soft power'. This soft power carries within a certain degree of indeterminacy, which has been noted as one pain of imprisonment (Crewe 2011b), when inmates cannot foresee what to do to obtain a benefit.

\section{Who Grants Them?}

I have argued that only $25.3 \%$ of the prisoners get a leave when they should (that is, upon reaching the $1 / 4$ stage of their sentence) and that most of the prisoners are granted leave at a very late stage in the sentence (with immigrants and some groups of offenders tending to be excluded). I have also pointed out that the criteria evaluated are a symbol of the psychological model, or 'soft power', now prevalent in Spanish prisons, together with the incorporation of the victim at the sentence implementation stage.

I now turn on to a third discussion regarding the authority to grant a prison leave. The system in Spain rests within a fragile balance between prison boards and the judiciary. While prison boards make the proposal, this is not binding and it is the penitentiary judges who finally grant prison leave. ${ }^{25}$ The intervention of judges began in Spain in 1979, after the dictatorship. Mistrust of the prison administration prompted the new penitentiary law to give this power to the judges.

What is remarkable in this 'mixed procedure' is the role that 'risk aversion' plays. The crucial factor is who appears accountable to public opinion as having granted the prison leave (in case things go very wrong). If something happens it is useful to say 'it was the judge who granted', in the same way that for the judge it is tranquilizing to say 'the administration had written a positive report'. The result of this 'mixed procedure' is that it sometimes tends to produce confusing results for the prisoner, who knows it has been approved by the prison board, and then is denied by the judge. However, whilst 'blame' might be allocated to the judge, it is the prison personnel in direct contact with the aggrieved prisoner who will have to explain the complicated procedures to them and, indeed, bear the consequences of a negative decision.

Which authority is in a better position to grant a prison leave? What are the arguments in favor of a system that defers to the Prison Board? Prison Boards tend to be closer to the prisoner and therefore might be in a better position to know the inmate. However, there are also some critical elements in giving Prison Boards this power. On the one hand, one should not overstate this 'closeness', because a common complaint is that psychologists do not spend

$\overline{{ }^{25} \text { Only if the leave is less than } 48 \mathrm{~h}}$, or the offender is in an open prison, it is granted directly by the prison board. 
much time with offenders. On the other hand, in my research (Larrauri 2019), ${ }^{26}$ I noticed that the psychologist, who explains the case to the prison board, might not necessarily be the one who is in close contact with the offender, so finally he has no 'close contact' either. Third, the prisoner has no voice during this internal procedure in front of the Prison Board, where his offence will be again described in detail, and his conduct in prison and social relations examined, without him having any say. In addition, it has also been noticed that it is not unusual that some practitioners on the Prison Board expect 'to turn prisoners into Guardian readers' (Perry 2013) and add a host of further requirements before granting leave. Finally, the explanations of the Prison Board given to the prisoner tend to be little more than an ' $\mathrm{X}$ ' on a sheet.

On the other hand, what are the arguments in favor of prison leave being decided by penitentiary judges? As I have mentioned it is the mistrust with prison administration that prompts the new penitentiary law of 1979 to give this power to the judges. However, it should be emphasized that in Spain judges only supervise positive reports, that is, the ones that the prison board has positively evaluated. ${ }^{27}$ This might seem paradoxical because when the penitentiary judge was introduced into the process, the main goal was to protect the rights of inmates; therefore, it would seem appropriate that judges should, in particular, supervise the reasons for negative reports.

One might assume that even this restricted judicial intervention is positive because judges would be more inclined to treating leave as a 'right' rather than as a 'reward', or even as a 'treatment tool'. Therefore judges could be paramount to producing a consistent, fair system of prison leave. However, before reaching this conclusion we would need more research to answer three questions: i. does judicial intervention result in more prison leave; ii. does judicial intervention achieve a higher degree of consistency; iii. Are the reasons evaluated by judges closer to the ideal of granting prison leave as a 'pilot test' for rehabilitation? I will very briefly provide some thoughts on each.

It is nowadays not clear if decisions by penitentiary judges result in more or less prison leave. Usually the intervention of the judges is thought as being more 'liberal'; however, this might depend on how 'liberal' Prison Boards actually are. While in Catalan prisons we might think that Prison Boards tend to suggest more prison leave, and judges appear to deny them, the situation might well be the opposite in the rest of Spain. It is therefore necessary to analyze whether judges tend to contradict Prison Boards or show deference to them by following their recommendations. ${ }^{28}$

Regarding the aim of consistent criteria, the results are also mixed. Once the positive evaluations are forwarded to penitentiary judges, some tend to agree with prison boards and see their role as supervising 'procedure' by asking questions such as: have all the reports been written, have the reasons for the decision been explained, has the reintegration goal been taken into account, and when risk is acknowledged can it be minimized without denying the prison leave? In others, however, judges (and prosecutors) once they have the positive report by the prison board, ask or evaluate many other additional requirements. Alas, judicial intervention does not seem to bring more consistency, because there is no unifying doctrine, so to the discretion of the Administration (Prisons Boards) we should add the layer of judicial discretion.

\footnotetext{
${ }^{26}$ I was able to attend as an observer at seven meetings of Prison Boards when prison leave was decided in three different prisons in Barcelona. I have not been granted permission to replicate this research in other parts of Spain.

${ }^{27}$ In the case the offender receives a negative report he has a right to appeal to a judge.

${ }^{28}$ Although I only speak of judges in order not to make the comprehension too difficult, public prosecutors are the ones that may, and often do, object to the positive proposals by the prison board. The judge then decides between the prison board and the public prosecutor, often in favor of the latter.
} 
Finally, regarding who is in a better position to evaluate the rehabilitation efforts, one could argue that Prison Boards will be more sensitive to performance inside prison (be it of a disciplinary or treatment nature), whereas judges will be more attuned to rehabilitation goals. However, probably due to their distance from the inmate or their legal background, judges tend to center their attention on 'rigid' criteria. These criteria are sometimes the level of risk provided by the RA tools where a medium or high risk level is, on occasions, enough to deny the prison leave. On other occasions these 'rigid' criteria arise from just deserts considerations like: time served, pending cases, the seriousness of the offence, or recidivism. This raises the discussion pursued by lawyers in Spain regarding whether it is appropriate for penitentiary institutions like prison leave to (re-)consider factors that have already been considered by the courts when setting the sentence.

The principle is that purely internal decisions about the regime should not be influenced directly by the length of the sentence or the seriousness of the offence. To the extent that prison leave is merely an internal matter, it should be granted in every case where it is necessary for achieving the positive effects of reducing the harmful effects of imprisonment and enabling prisoners to lead a useful and crime free life (...) (van Zyl Smit and Snacken 2009 :322-323).

In sum, in Spain a prison leave is recommended by the Prison Board and granted by the penitentiary judge. This results in a mixed system that produces confusing results for prisoners. A positive prison report might be followed by a negative judicial response. ${ }^{29}$ This is due mainly to the fact that judges evaluate and add requirements that are not stated in the law, and that may not have been considered decisive by the Prison Board. Altogether, the lack of clear and consistent criteria and the intervention of two authorities is what raises serious criticisms about the system of prison leave.

\section{Discussion}

I have explained that prison leave is the key element of the Spanish system of early release. In addition, prison leave is a well-known institution in Spain. Prisoners have expectations of enjoying leave and it is part of what inmates consider when they value Quality of Prison Life (Rodríguez et al. 2018). ${ }^{30}$ It forms part of the experience of what it is to be a prisoner with prison life in Spain revolving around who gets leave, who does not, when, and why.

When we asked prisoners about the three most negative things in prison (following the original Measuring Quality of Prison Life survey, and after the classification of the openanswers by topic) the 'criteria for obtaining prison benefits', mostly referring to prison leave, was the second most mentioned topic with $37.3 \%$ of prisoners raising it as an issue (Rovira et al. 2018). This negative view is probably due to its multiple and confusing eligibility criteria and procedures.

In order to understand their frustration, I have explained how the administration of the prison leave works. I have pointed out that the psychological model of rehabilitation dominates eligibility for prison leave. These criteria are mainly a symbol of the psychological model, or 'soft power', now prevalent in Spanish prisons, together with the incorporation of the victim at

${ }^{29}$ Of course when the offender appeals, it might be the other way around.

30 The reference is of course to Liebling (2004). 
the sentence implementation stage. Thus, in Spanish prisons, leave is a good example of 'soft power' that has been criticized (Crewe, 2011) on grounds of lack of clarity and transparency.

Since Jacobs (1977), it is common to consider prison as a modern 'rational-legal bureaucracy,. ${ }^{31}$ However, the administration of prison leave in Spain demonstrates that even rationallegal bureaucracies vest their decision makers with a great deal of discretionary authority that may be exercised unevenly, even arbitrarily. This raises further questions about whether this discretionary power can be supervised, and structured; whether the 'rational legal bureaucracy' model of prison is hindered by the psychological model of rehabilitation; and whether the legal model also has to rely on 'incentives' instead of 'rights'. As Livingstone and Owen, (Livingstone and Owen 1993:309) point out:

Liberal 'treatment-orientated' regimes can just as easily fall foul of judicial imperatives as harsh, authoritarian regimes. This is because treatment orientated regimes also require individualized and frequently unequal treatment of prisoners.

To conclude, a properly administered system of prison leave may also contribute to legitimacy if prisoners see it as procedurally fair. Legitimacy has been studied in relation to courts and police (Tyler 1990). Some authors have also highlighted its importance in prison management (Sparks and Bottoms 1995; Reisig and Mesko 2009; Franke et al. 2010; Johnson et al. 2014; Liebling 2014; Brunton-Smith and McCarthy, 2016; Beijesbergen et al. 2016).

Legitimacy is important because (in its simplest definition) it diminishes the need to resort to coercive methods in order to achieve compliance. ${ }^{32}$ I agree that legitimacy also plays a role in prison, a setting where order is not only achieved through force, incentives, and dull compulsion (Carrabine 2005) but also through normative reasons (Sparks and Bottoms, 2008). ${ }^{33}$

According to Tyler (1990), legitimacy is enhanced when people feel treated in a 'procedurally just manner' (Beijesbergen et al. 2015). In McCarthy and Brunton-Smith's (2018) words

Procedural fairness can be described as the combination of the decision-making process (i.e., whether people are treated fairly and perceive legal procedures to have been followed correctly) and the quality of treatment received (i.e., being treated with respect and dignity).

As our research suggests, the contemporary system of prison leave might be experienced in Spain as 'procedurally unfair'. On the one hand, regarding the 'quality of treatment' dimension, the administration of prison leave strains the relations of inmates with prison officers, especially with treatment personnel. These are sometimes accused of being 'dream sellers' because, according to some prisoners', treatment personnel sometimes 'promise' a prison leave in return for attendance on a cognitive behavioral program, which is not ultimately delivered. Thus, whilst 'blame' for refusal to grant a leave might be allocated to the judge as

\footnotetext{
${ }^{31}$ Barak-Glantz (1981) also describes the move from an authoritarian to a 'bureaucratic-lawful' model. However, we would certainly agree that this transformation has hardly reduced discretion.

32 Other authors (Beijesbergen et al. 2016) point to the possibility of legitimacy affecting reoffending rates. For a discussion see McCarthy and Brunton-Smith (2018).

33 These authors explain how the Woolf commission (1991) created in the UK after the riots explained these partly as a result of the sense of injustice. Also Goldstone and Useem (1999) and Useem and Goldstone (2002) when explaining riots in the US underline the sense of injustice and the need to maintain legitimacy.
} 
the final authority who grants it (as explained earlier) it is the prison personnel, in direct contact with the aggrieved prisoner who often bear the consequences of a negative decision.

On the other hand, increasing procedural justice in prison is not only a matter of emphasizing the relational aspects (respect, decency, and trust) but also depends on the 'quality of the decision'. ${ }^{34}$ Prison leave increases legitimacy when prisoners think it operates fairly (because the eligibility criteria are transparent and the procedures fair). If leave is granted, or is perceived to be granted arbitrarily, the gain for the beneficiaries could be offset (Toch 1967) by decreased legitimacy and increased cynicism. The legitimacy of the prison regime increases to the extent that prisoners believe that prion leave is administered fairly.

Open Access This article is licensed under a Creative Commons Attribution 4.0 International License, which permits use, sharing, adaptation, distribution and reproduction in any medium or format, as long as you give appropriate credit to the original author(s) and the source, provide a link to the Creative Commons licence, and indicate if changes were made. The images or other third party material in this article are included in the article's Creative Commons licence, unless indicated otherwise in a credit line to the material. If material is not included in the article's Creative Commons licence and your intended use is not permitted by statutory regulation or exceeds the permitted use, you will need to obtain permission directly from the copyright holder. To view a copy of this licence, visit http://creativecommons.org/licenses/by/4.0/.

\section{References}

Barak-Glantz, I. L. (1981). Toward a conceptual schema of prison management styles. The Prison Journal, 61(2), $42-60$.

Baumer, E. P., O’Donnell, I., \& Hughes, N. (2009). The porous prison. A note on the rehabilitative potential of visits home. The Prison Journal, 89, 1.

Beijesbergen, K. A., Dirkzwager, A., Eichelsheim, V., Van der Laan, P., \& Nieuwbeerta, P. (2015). Procedural justice, anger, and prisoners' misconduct. Criminal Justice and Behavior, 42(2), 196-218.

Beijesbergen, K. A., Dirkzwager, A., \& Nieuwbeerta, P. (2016). Reoffending after release. Does procedural justice during imprisonment matter? Criminal Justice and Behavior, 43(1), 63-82.

Brunton-Smith, I., \& McCarthy, D. (2016). Prison legitimacy and procedural fairness: A multilevel examination of prisoners in England and Wales. Justice Quarterly, 33(6), 1029-1054.

Caballero, J. J. (1981). La Conflictividad en las prisiones españolas: una perspectiva histórica y sociológica, Revista Estudios Penitenciarios, 121-168.

Carrabine, E. (2005). Discourse, govermentality and translation. Theoretical Criminology, 4(3), 309-331.

Cheliotis, L. (2005). The prison furlough programme in Greece. Punishment and Society, 7(2), 201-215.

Cheliotis, L. (2009). Before the next storm. Some evidence-based reminders about temporary release. International Journal Offender Therapy and Comparative Criminology, 53(4), 420-432.

Cid, J.\&Ibàñez, A. (2019). Prisoner resettlement in Spain - Good practices for early-released prisoners and prisoners lost in transition that fully serve their sentence, in Dünkel, F., Pruin I., Storgaard, A., and Weber J. (eds.), Prisoner Resettlement in Europe. Routledge.

Crewe, B. (2011a). Soft power in prison: Implications for staff-prisoner relationships, liberty and legitimacy. European Journal of Criminology, 8(6), 455-468.

Crewe, B. (2011b). Depth, weight, tightness: Revisiting the pains of imprisonment. Punishment \& Society, 13(5), 509-530.

Crewe, B. (2015). Inside the belly of the penal beast: Understanding the experience of imprisonment. International Journal for Crime, Justice and Social Democracy, 4(1), 50-65.

Duff, A. (2001). Punishment, communication, and community. Oxford: Oxford University Press.

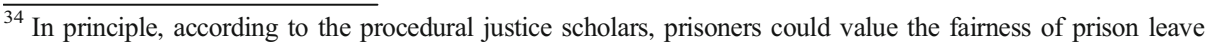
independently if they themselves have benefited from one. However, some scholars dispute the clarity of the distinction between procedural and distributive justice in general: "The fact that the perception of distributive fairness often has less to do with an outcome's exchange value than with its symbolic or status value is one reason it has proven so difficult to draw a sharp distinction between procedural and distributive injustice" (Miller 2001:530).
} 
Dünkel, F., \& Van Zyl, D. (2001). Imprisonment today and tomorrow: International perspectives on prisoners' rights and prison conditions (2nd.ed ed.). The Hague: Kluwer.

Downes, D. M. (1988). Contrasts in tolerance. Oxford: Clarendon.

Fox, K. J. (1999). Changing violent minds: Discursive correction and resistance in the cognitive treatment of violent offenders in prison. Social Problems, 46(1), 88-103.

Franke, D. F., Bierie Layton, D., \& Mackenzie, D. (2010). A randomized Experiment comparing a boot camp with a prison. Criminology \& Public Policy, 9, 1.

Goldstone, J. A., \& Useem, B. (1999). Prison riots as microrevolutions: An extension of state-centered theories of revolution. American Journal of Sociology, 104(4), 985-1029.

Hacin, R., Fields, C., \& Mesko, G. (2019). The self-legitimacy of prison staff in Slovenia. European Journal of Criminology, 16, 1: 41-60

Helmus, L. M., \& Ternes, M. (2017). Temporary absences from prison in Canada reduce unemployment and reoffending: Evidence for dosage effects from an exploratory study. Psychology, Public Policy, and Law, 23(1), 23-38.

Jacobs, J. B. (1977). Stateville. Chicago: The University of Chicago Press.

Johnson, D., Maguire, E., \& Kuhns, J. B. (2014). Public perceptions of the legitimacy of the law and legal authorities: Evidence from the Caribbean. Law \& Society Review, 48, 4.

Kemshall, H. (2011). Crime and risk: Contested territory for risk theorising. International Journal of Law, Crime and Justice, 39, 218-229.

Larrauri, E. (2019). 'Se Inventan Sus Leyes': ¿Qué Criterios se Deben Valorar En La Concesión De Permisos De Salida Penitenciarios?, Jueces para la Democracia.

Larrauri, E., Rovira, M. \& Sales, A. (2017). Qualitat de vida als centres penitenciaris i programes d'intervenció. Centre d'Estudis Jurídics i Formació Especialitzada.

Liebling, A. (2004). Prisons and their moral performance: A study of values, quality and prison life. Oxford: Oxford University Press.

Liebling, A. (2014) 'Legitimacy under Pressure' in High security prisons, Tankebe,J.; libeling a. (eds) Legitimacy and Criminal Justice: An International Exploration, Oxford Scholarship Online.

Livingstone, S., \& Owen, T. (1993). Prison law. Oxford: Clarendon Press.

Maruna, S., \& Mann, R. (2006). A fundamental attribution error? Rethinking cognitive distortions. Legal and Criminological Psychology, 11, 155-177.

Maruna, S., \& Copes, H. (2004). What have we learned from five decades of neutralization research? Crime and Justice, 32, 221-320.

McCarthy, D., \& Brunton-Smith, I. (2018). The effect of penal legitimacy on prisoners' Postrelease desistance. Crime \& Delinquency, 64(7), 917-938.

Miller, D. T. (2001). Disrespect and the experience of injustice. Annual Review Psychology, 52, 527.53.

Mine, B., \& Robert, L. (2015). L'octroi des permissions de sortie et du congé penitentiaire en Belgique, Schwizerische Zetischrift für Kriminologie, Heft 1/2015.

Monahan, J., \& Skeem, J. L. (2016). Risk assessment in criminal sentencing. Annual Review of Clinical Psychology, 12, 489-513.

Moran, D., \& Keinänen, A. (2012). The 'inside' and 'outside' of prisons: Carceral geography and home visits for prisoners in Finland. Fennia, 190(2), 62-76.

Neira, N. (2015). Permisos ordinarios de salida de duración inferior a dos días. Estudio sobre los criterios subjetivos de valoración empleados por la Administración Penitenciaria Catalana». Indret Criminología. 125.

Perry, E. (2013). 'We're not trying to turn them into middle-class Guardian readers': Constructing the offender in the probation 'classroom'. British Journal of Sociology of Education, 34(4), 525-543.

Reisig, M., \& Mesko, G. (2009). Procedural justice, legitimacy, and prisoner misconduct. Psychology, Crime \& Law, 15(1), 41-59.

Rodríguez, J., Larrauri, E., \& Güerri, C. (2018). Percepción de calidad de vida en prisión: La importancia de una buena organización y un trato digno. Revista Internacional de Sociología, 76(2), e098.

Rodríguez de Santiago, J. M. (2016). Metodología del derecho administrativo. Madrid: Marcial Pons.

Rovira, M., Larrauri, E., \& Alarcón, P. (2018). La concesión de permisos penitenciarios. Una aproximación criminológica a distintas fuentes de variación. Revista Electrónica de Ciencia Penal y Criminología, RECPC 20-02.

Schinkel, M. (2014). Punishment as moral communication: The experiences of long-term prisoners. Punishment and Society, 16(5), 578-598.

Simon, J. (2000). The 'society of captives' in the era of hyper-incarceration. Theoretical Criminology, 4(3), 285308 .

Snacken, et al. (2014). Prisons and punishment in Europe, The Routledge Handbook of European Criminology, body-Gendrot, S. et al., Routledge, London. 
Sparks, J. R., \& Bottoms, A. E. (1995). Legitimacy and order in prisons. British Journal of Sociology, 46/1, 4562.

Sparks, J. R., \& Bottoms, A. E. (2008). Legitimacy and imprisonment revisited: Some notes on the problem of order ten years later. In J. Byrne, D. Hummer, \& F. Taxman (Eds.), The culture of prison violence. Boston: Pearson/Allyn and Bacon.

Toch, H. (1967). Prison inmates' reactions to furlough. Journal of Research in Crime and Delinquency, 4, 248262.

Tyler, T. R. (1990). Why people obey the law. New Haven: Yale University Press.

van Zyl Smit, D. (1988). Leave of absence for west German prisoners. The British Journal of Criminology, 28(1), $1-18$.

van Zyl Smit, D. Y., \& Snacken, S. (2009). Principles of European prison law and policy: Penology and human rights. Oxford: Oxford University Press.

Useem, B., \& Goldstone, J. (2002). Forging social order and its breakdown: Riot and reform in U.S. prisons. American Sociological Review, 67(4), 499-525.

Publisher's Note Springer Nature remains neutral with regard to jurisdictional claims in published maps and institutional affiliations. 